\title{
A CONSTRAINED STOCHASTIC PRODUCTION PLANNING PROBLEM WITH IMPERFECT INFORMATION OF INVENTORY
}

\author{
Oscar S. Silva Filho \\ Centro de Pesquisas Renato Archer \\ Rod. D. Pedro I, Km. 143,6 \\ 13089-500 - Campinas - São Paulo - Brazil \\ Email: oscar.salviano@cenpra.gov.br
}

\begin{abstract}
In this paper, an aggregate production planning problem is formulated as a chance-constrained stochastic control problem under imperfect information of states (i.e., the inventory levels). Using the Kalman filter device, the mean and covariance of state variables are estimated. Then the certainty equivalence principle is applied, resulting in a deterministic problem that is equivalent to the original formulation. In order to provide a sequential optimal solution to the equivalent problem, the Naive Feedback Controller (NFC) approach is used. It provides a revised sub-optimal production policy to the stochastic problem. An example illustrates the applicability of this approach.Copyright@2005 IFAC
\end{abstract}

Keywords: production planning, inventory system, imperfect information, suboptimal controller, Kalman filter

\section{INTRODUCTION}

One of the first actions in a hierarchical decision chain is the elaboration of an aggregated production plan, see Hax and Candea (1985) and Tsubone, et al. (1991). The basic idea of this plan is to identify the quantity of inventory and workforce (man hour) levels that will be required by the company to produce its products at future periods. Surely, this is not an easy task even for an expert manager. The reason is that there are a variety of uncertainties associated with the process of identifying the quantity of the raw-materials required to be used in the shop floor. These uncertainties are due to exogenous and endogenous factors. For example, exogenous factors are to know a priori if a given supplied material will be considered appropriate to consume during the quality test; or to know precisely how will be the behavior of demand in the next month. On the other hand, endogenous factors are related to the quantity of material lost or robbed during its handle in the storeroom. As a direct consequence of the exogenous and endogenous randomness, the inventory levels of products may not be measured precisely. Thus, in order to deal with the lack of accuracy about inventory, a stochastic optimal control problem under hypothesis of imperfect information of state must be formulated, see (Kleindorfer, 1978; Neck, 1984; Bertesekas, 1995).

This paper introduces a stochastic dynamic optimization model to solve a multi-product, multiperiod production planning problem with constraints on decision variables (i.e. inventory, workforce and production levels) and finite planning horizon. It is assumed that inventory levels are not known exactly; as a result the inventory levels need to be estimated. Thus, under an assumption of Gaussian uncertainties, the implementation of a Kalman filter (Astron, 1970) for estimating the inventory levels, is quite 
convenient. The Gaussian nature of system and measurement equations brings also, as a consequence, that the inventory constraints are taken in conditional probability in order to guarantee the feasibility of the inventory levels.

The dimensionality and stochastic nature of the system as a whole, with additional assumption of the imperfect information of inventory levels, are factors that bring extreme complexity to the problem solution. A way to overcome this difficulty is to use the Gaussian-Markov properties of the system and measurement equations to convert the original sequential stochastic problem into a deterministic equivalent problem that includes explicitly the associated conditional mean and covariance inventory variables.

A true optimal sequential solution (i.e. optimal feedback solution) of this equivalent problem is practically impossible to obtain, primarily due to both dimensionality (especially in practical cases) and constraints involved. Consequently, it is necessary to investigate alternatives that will make the problem easier to be solved, mainly taking into consideration the application of mathematical programming methods available in the literature (Minoux, 1983).

Optimal solutions based on sub-optimal procedures can be an interesting field of investigation (Bertesekas, 1995). In this way, a sub-optimal approach named as Naive Feedback Controller (NFC) is considered in this paper. It is easier for numerical implementations than other sub-optimal methods, see Silva Filho and Cezarino (2002). Besides, it allows that the solution of the problem can be revised periodically. For production application, this means that the aggregated plan must be constantly revised; as a consequence, managerial insights about the dynamic of production environment can be improved, see Silva Filho (2001) and Silva Filho and Ventura (1999).

An illustrative example that provides a production plan for two different families of products is introduced. The idea is to compare the sub-optimal solution of the stochastic problem under imperfect information of state (i.e. inventory level) provided by the NFC approach to the sub-optimal solutions provided by the Open-loop and NFC approaches applied to the same problem but under perfect information of state. As a result, the quasi-adaptivity propriety of the NFC approach (Bertesekas, 1995) is possible to be shown.

\section{STOCHASTIC DYNAMIC PROBLEM}

An optimal production planning described by the sequence $\left\{\left(\mathrm{u}_{\mathrm{i} 1} \mathrm{u}_{\mathrm{i} 2} \ldots \mathrm{u}_{\mathrm{iT}}\right) ; \mathrm{i}=1,2, \mathrm{~N}\right\}$ can be obtained by solving the following multi-product multi-period stochastic production planning problem:

$$
\begin{aligned}
& \underset{\mathrm{u}_{\mathrm{ik}}}{\operatorname{Min}} \sum_{\mathrm{i}=1}^{\mathrm{N}}\left\{\sum_{\mathrm{k}=0}^{\mathrm{T}} \mathrm{E}\left[\mathrm{f}\left(\mathrm{x}_{\mathrm{ik}} \mid \mathrm{I}_{\mathrm{ik}}\right)\right]+\sum_{\mathrm{k}=0}^{\mathrm{T}-1} \mathrm{~g}\left(\mathrm{u}_{\mathrm{ik}}\right)\right\}+\sum_{\mathrm{k}=0}^{\mathrm{T}-1}\left[\mathrm{r}\left(\mathrm{w}_{\mathrm{k}}\right)+\mathrm{p}\left(\mathrm{z}_{\mathrm{k}}\right)\right] \\
& \quad \mathrm{x}_{\mathrm{i}, \mathrm{k}+1}=\mathrm{x}_{\mathrm{ik}}+\mathrm{u}_{\mathrm{ik}}-\mathrm{d}_{\mathrm{ik}} ; \mathrm{x}_{\mathrm{i} 0}=\mathrm{E}\left(\mathrm{x}_{\mathrm{i} 0} \mid \mathrm{I}_{\mathrm{k}}\right) \\
& \quad \mathrm{y}_{\mathrm{i}, \mathrm{k}}=\mathrm{x}_{\mathrm{ik}}+\mathrm{v}_{\mathrm{ik}} \\
& \quad \operatorname{Pr} \mathrm{ob} .\left(\mathrm{x}_{\mathrm{ik}} \geq \underline{\mathrm{x}}_{\mathrm{ik}} \mid \mathrm{I}_{\mathrm{ik}}\right) \geq \alpha_{\mathrm{ik}} ; \alpha_{\mathrm{ik}} \in[0,1) \\
& \quad \sum_{\mathrm{i}=1}^{\mathrm{N}} \eta_{\mathrm{i}} \cdot \mathrm{u}_{\mathrm{ik}}-\mathrm{w}_{\mathrm{k}}-\mathrm{z}_{\mathrm{k}}=0 \\
& \quad \sum_{\mathrm{i}=1}^{\mathrm{N}} \pi_{\mathrm{i}} \cdot \mathrm{u}_{\mathrm{ik}} \leq \overline{\mathrm{U}} \\
& \quad \mathrm{u}_{\mathrm{ik}}, \mathrm{z}_{\mathrm{k}} \geq 0 \text { and } 0 \leq \mathrm{w}_{\mathrm{k}} \leq \overline{\mathrm{W}}_{\mathrm{k}}
\end{aligned}
$$

where $\mathrm{N}$ is number of different product families and $\mathrm{T}$ denotes the planning horizon (assumed as finite). For each product $\mathrm{i}$ in period $\mathrm{k}$, the decision variables, cost functions and parameters have the following notation: $\mathrm{u}_{\mathrm{ik}}$ is the production level; $\mathrm{x}_{\mathrm{ik}}$ is the inventory level; $\mathrm{w}_{\mathrm{k}}$ is the work-force level (manhour); $z_{k}$ is the overtime (man-hour); $y_{k}$ denotes the observation level of inventory measurement; $d_{i k}$ is the demand level by products; $v_{i k}$ denotes the measure error. The costs incurred are: $\mathrm{f}\left(\mathrm{x}_{\mathrm{ik}}\right)$ is inventory cost; $\mathrm{g}\left(\mathrm{u}_{\mathrm{ik}}\right)$ is the production cost; $\mathrm{p}\left(\mathrm{v}_{\mathrm{k}}\right)$ denotes the workforce cost. Other parameters are: $\mathrm{W}_{\mathrm{k}}$ is the maximum number of regular work force (in man hour); $\alpha_{i k}$ is the confidence level (probability degree); $\eta_{i}$ is the manhour required to produce one unit of product $i ; \pi_{i}$ is the productivity factor; $\mathrm{x}_{\mathrm{i} 0}$ is the initial inventory; $\mathrm{I}_{\mathrm{ik}}$ is the information available at period $\mathrm{k}$; and $\mathrm{E}($.) denotes expectation value operator.

The demand variable $\mathrm{d}_{\mathrm{ik}}$ must be understood as being a stochastic component of the inventory balance system. Particularly, the evolution of demand over the periods follows a stationary Gauss-Markov process where the independent random variables $d_{i j}$ have mean $\mathrm{E}\left(\mathrm{d}_{\mathrm{ij}}\right)=\mu_{\mathrm{d}_{\mathrm{i}}}$ and time-invariant variance $\operatorname{Var}\left(\mathrm{d}_{\mathrm{ij}}\right)=\sigma_{\mathrm{d}_{\mathrm{i}}}^{2} \geq 0$. It is worth emphasizing that such process has been used, in practice, to represent product demands determined by a prior forecasting device or even from an historical of customers' orders (i.e., historical of sales).

Since inventory level is not perfectly measured, an output system given by (3) is used to provide a measurement device that captures information about inventory variable with error $v_{i k}$. This error is defined as a normal distributed random variable, with mean $\hat{\mathrm{v}}_{\mathrm{k}}=0$ and finite variance $\sigma_{\mathrm{v}}^{2}>0$. The constraint (4) defines a safety stock $\left(\underline{x}_{i k}\right)$ associated with product $\mathrm{i}$, at period $\mathrm{k}$. It is used as a guarantee that future, and consequently uncertain, demands will be met. This constraint is taken as a chance-constraint in order to ensure that the inventory level for product $i$ is greater or equal than $\underline{x}_{i k}$ with conditional probability of at 
least $\alpha_{i k}$ at each time period $\mathrm{k}$, given history $\mathrm{I}_{\mathrm{ik}}$ of the system. The constraint (5) denotes the total manpower to be used in every period $\mathrm{k}$ of planning horizon T. The capacity constraint (6) considers that the summation of production levels in every period $\mathrm{k}$ must not overcome the total capacity of the system $\overline{\mathrm{U}}$.

Solving the optimization model (1)-(7) is a hard task due to the dimensionality and sequential stochastic nature of the system whose states (inventory variables) are not exactly measured. An alternative to is a sub-optimal approach, as discussed in (Bertesekas, 1995) and (Kleindorfer, 1978). The next section discusses about NFC approach applied to problem (1)-(7).

\section{THE SUB-OPTIMAL PROCEDURE}

Since the stochastic problem (1)-(7) is under the hypothesis of imperfect information of states, the inventory levels are not directly accessible for control purposes. As a consequence, it is required primarily to estimate the inventory levels, before applying the NFC procedure.

\subsection{Estimating the Inventory levels: The Kalman Filter.}

Firstly, it is important to introduce the vector $\mathrm{I}_{\mathrm{k}}$. It contains all current, and past information related to output $\mathrm{y}_{\mathrm{ik}}$ and production $\mathrm{u}_{\mathrm{ik}}$ variables. In literature, it is known as sufficient statistic because all information available for providing a control policy depends on it. Thus, it can be defined as follows (Bertesekas, 1995):

$$
\mathrm{I}_{\mathrm{ik}}=\left\{\mathrm{u}_{\mathrm{i} 0}, \mathrm{u}_{\mathrm{i} 1}, \ldots, \mathrm{u}_{\mathrm{i}, \mathrm{k}-1}, \mathrm{y}_{\mathrm{i} 0}, \mathrm{y}_{\mathrm{il}}, \ldots, \mathrm{y}_{\mathrm{ik}}\right\} \supset \mathrm{I}_{\mathrm{i}, \mathrm{k}-1}
$$

Since the structure of the system (2)-(3) is linear and the random variables (i.e. demand fluctuation and error measurement variables) involved are Gaussian distributions, the conditional probability distribution function of the inventory $\left(\mathrm{x}_{\mathrm{ik}}\right)$, given the sufficient statistic $\left(\mathrm{I}_{\mathrm{k}}\right)$, will be also Gaussian. As a result, all information required to estimate the inventory levels are reduced to conditional mean and covariance that are generated over the time from the Kalman filter, as follows (Astron, 1970)

$$
\begin{aligned}
\mathrm{x}_{\mathrm{k}+1 \mid \mathrm{k}+1}^{\mathrm{i}}= & \mathrm{x}_{\mathrm{k} \mid \mathrm{k}}^{\mathrm{i}}+\mathrm{u}_{\mathrm{ik}}+\hat{\mathrm{d}}_{\mathrm{ik}}+ \\
& \mathrm{V}_{\mathrm{x}_{\mathrm{i}}^{\mathrm{k}+1 \mid \mathrm{k}}} \cdot\left(\mathrm{V}_{\mathrm{x}_{\mathrm{i}}}^{\mathrm{k}+1 \mid \mathrm{k}}+\sigma_{\mathrm{v}}^{2}\right)^{-1} \cdot\left[\mathrm{y}_{\mathrm{k}+1}-\mathrm{x}_{\mathrm{k}+1 \mid \mathrm{k}}^{\mathrm{i}}-\mathrm{u}_{\mathrm{ik}}+\hat{\mathrm{d}}_{\mathrm{ik}}\right]
\end{aligned}
$$

and,

$$
\left\{\begin{array}{l}
\mathrm{V}_{\mathrm{x}_{\mathrm{i}}}^{\mathrm{k}+1 \mid \mathrm{k}+1}=\mathrm{V}_{\mathrm{x}_{\mathrm{i}}}^{\mathrm{k}+1 \mid \mathrm{k}}-\mathrm{V}_{\mathrm{x}_{\mathrm{i}}}^{\mathrm{k}+1 \mid \mathrm{k}} \cdot\left(\mathrm{V}_{\mathrm{x}_{\mathrm{i}}}^{\mathrm{k}+1 \mid \mathrm{k}}+\sigma_{\mathrm{V}}^{2}\right)^{-1} \cdot \mathrm{V}_{\mathrm{I}}^{\mathrm{k}+1} \\
\mathrm{~V}_{\mathrm{x}_{\mathrm{i}}}^{\mathrm{k}+1 \mid \mathrm{k}}=\mathrm{V}_{\mathrm{x}_{\mathrm{i}}}^{\mathrm{k} \mid \mathrm{k}}+\sigma_{\mathrm{D}}^{2}
\end{array}\right.
$$

where $\mathrm{x}_{\mathrm{k} \mid \mathrm{k}}^{\mathrm{i}}=\mathrm{E}\left\{\mathrm{x}_{\mathrm{ik}} \mid \mathrm{I}_{\mathrm{ik}}\right\}$ and $\mathrm{V}_{\mathrm{x}_{\mathrm{i}}}^{\mathrm{k} \mid \mathrm{k}}=\mathrm{E}\left\{\left(\mathrm{x}_{\mathrm{ik}}-\mathrm{x}_{\mathrm{k} \mid \mathrm{k}}^{\mathrm{i}}\right)^{2}\right.$ denotes respectively the conditional mean and covariance estimates of inventory variables.

The initial conditions for (6) and (7) are given by:

$$
\left\{\begin{array}{l}
\mathrm{x}_{0 \mid 0}^{\mathrm{i}}=\hat{\mathrm{x}}_{\mathrm{i} 0}+\mathrm{V}_{\mathrm{x}_{\mathrm{i}}}^{0 \mid 0} \cdot\left(\sigma_{\mathrm{v}}^{2}\right)^{-1} \cdot\left(\mathrm{y}_{\mathrm{i} 0}-\hat{\mathrm{x}}_{\mathrm{i} 0}\right) \\
\mathrm{V}_{\mathrm{x}_{\mathrm{i}}}^{0 \mid 0}=\mathrm{V}_{\mathrm{x}_{\mathrm{i}}}^{0}-\mathrm{V}_{\mathrm{x}_{\mathrm{i}}}^{0} \cdot\left(\mathrm{V}_{\mathrm{x}_{\mathrm{i}}}^{0}-\sigma_{\mathrm{v}}^{2}\right)^{-1} \cdot \mathrm{V}_{\mathrm{x}_{\mathrm{i}}}^{0}
\end{array}\right.
$$

where $\hat{\mathrm{x}}_{\mathrm{i} 0}=\mathrm{E}\left\{\mathrm{x}_{\mathrm{i} 0}\right\}$ and $\mathrm{V}_{\mathrm{x}_{\mathrm{i}}}^{0}=\mathrm{E}\left\{\left(\mathrm{x}_{\mathrm{i} 0}-\hat{\mathrm{x}}_{\mathrm{i} 0}\right)^{2}\right\}$, denotes respectively the mean and covariance of the initial state $\mathrm{x}_{\mathrm{i} 0}$.

The equations (9) and (10) concentrate all available information about the current state of the inventory in the balance system (2), that is, the sufficient statistic required to develop a control rule (or production policy) to the problem (1)-(7).

In order to allow the application of NFC procedure, the original problem is initially transformed to an equivalent deterministic problem (Silva Filho and Ventura., 1999). Such a transformation is shortly discussed in following.

\subsection{The Deterministic Equivalent Problem}

Using the statistics of the demand fluctuation $\left(\mathrm{d}_{\mathrm{ik}}\right)$ and the error measurement $\left(\mathrm{v}_{\mathrm{ik}}\right)$ variables, the linearity of system (2)-(3), and the convexity of criterion, the stochastic problem (1)-(7) can be converted into an equivalent deterministic problem, named here as Mean Value Problem (MVP). Thus, using the conditional mean and variance estimation (9)-(11) provided by Kalman filter, the following transformations can be introduced:

a) on the criterion:

$$
\begin{aligned}
& E\left\{\sum_{k=0}^{T} f\left(x_{i k} \mid I_{i k}\right)\right\}=\sum_{k=0}^{T} \cdot E\left\{f\left(x_{i k} \mid I_{i k}\right)\right\}= \\
& =\sum_{k=0}^{T} E\left\{f\left(\hat{x}_{i k}+\varepsilon_{x_{i k}} \mid I_{i k}\right)\right\}=\int_{-\infty}^{+\infty} f\left(\hat{x}_{i k}+\tau \mid I_{k}\right) \cdot \rho_{\varepsilon_{x}}(\tau) \cdot \partial \tau= \\
& =\int_{-\infty}^{+\infty} f\left(\hat{x}_{i k}+\tau \mid I_{i k}\right) \cdot \partial \Phi_{\varepsilon_{x}}=F\left(\hat{x}_{i k}\right)+\sum_{i=1}^{N} K_{i}
\end{aligned}
$$

where $\hat{x}_{i k}=E\left\{x_{k \mid k}^{i}\right\}=E\left\{E\left[x_{i k} \mid I_{i k}\right]\right\}$ is the average value related to the state estimation, $\rho_{\varepsilon_{\mathrm{x}}}(\cdot)=\frac{\partial}{\partial \tau} \Phi_{\varepsilon_{\mathrm{x}}}($.$) denotes the density function of$ the random variable $\varepsilon_{\mathrm{x}_{\mathrm{ik}}}=\mathrm{x}_{\mathrm{k} \mid \mathrm{k}}^{\mathrm{i}}-\hat{\mathrm{x}}_{\mathrm{ik}}$. The term $\mathrm{K}_{\mathrm{i}}$ denotes the integration constant. It is important to say that such constant depends on the conditional variance $\mathrm{V}_{\mathrm{x}_{\mathrm{i}}}^{\mathrm{k} / \mathrm{k}}$. 
b) on the inventory balance equation:

Once having fixed $\mathrm{d}_{\mathrm{ik}}=\hat{\mathrm{d}}_{\mathrm{ik}}$, the transformation is immediate and it is given by :

$$
\hat{\mathrm{x}}_{\mathrm{i}, \mathrm{k}+1}=\hat{\mathrm{x}}_{\mathrm{ik}}+\hat{\mathrm{u}}_{\mathrm{ik}}-\hat{\mathrm{d}}_{\mathrm{ik}} ; \quad \hat{\mathrm{x}}_{\mathrm{i} 0}=\mathrm{E}\left(\mathrm{x}_{\mathrm{i} 0} \mid \mathrm{I}_{\mathrm{k}}\right)
$$

Note that $\mathrm{u}_{\mathrm{ik}}=\hat{\mathrm{u}}_{\mathrm{ik}}$ and $\operatorname{Var}\left(\mathrm{u}_{\mathrm{ik}}\right)=0$. It is worth mentioning that the plan provided by MVP will be an open-loop policy.

c) on the chance- constraint:

Let the constraint Prob. $\left(\mathrm{x}_{\mathrm{ik}} \geq \underline{\mathrm{x}}_{\mathrm{ik}} \mid \mathrm{I}_{\mathrm{ik}}\right) \geq \alpha_{\mathrm{ik}}$. From (9), (10), and (13) is possible to handle the probabilistic operator in (4) to obtain the following inequality. Note that is an usual procedure provided from the probability and statistics theory applied to decision-making, see Papoulis (1991) and Chow (1972) for more details:

$$
\hat{\mathrm{x}}_{\mathrm{ik}} \geq \underline{\mathrm{x}}_{\mathrm{ik}}+\sigma_{\mathrm{d}_{\mathrm{i}}} \cdot \sqrt{\mathrm{k}} \cdot \Phi_{\varepsilon_{\mathrm{x}}}^{-1}\left(\alpha_{\mathrm{ik}}\right)=\underline{\mathrm{x}}_{\alpha}^{\mathrm{i}}(\mathrm{k})
$$

where $\underline{x}_{\alpha}^{\mathrm{i}}(\mathrm{k})$ denotes a safe-stock function. It represents a lower bound level for the inventory variable. Note that the magnitude of the $\underline{x}_{\alpha}^{\mathrm{i}}(\mathrm{k})$ increases proportionally with period $\mathrm{k}$, standard deviation $\sigma_{\mathrm{d}_{\mathrm{i}}}$, and with parameter $\alpha_{\mathrm{ik}}$. This behavior can be understood as being a protective way of dealing with possible excess of demand over the future periods of planning horizon.

The reason for using (9) is that the production decision variable is an essentially deterministic variable; and, therefore, it is not responsive to the actual fluctuation of demand. Then, the safe stock $\underline{x}_{\alpha}^{\mathrm{i}}(\mathrm{k})$ is to be used as a barrier against stockout or backlogging situations. Thus, the possibility of failing to meet demand is reduced at any period. Additionally, it is possible to adjust the size of this safety stock. In this case, the manager can choose an adequate value for $\alpha_{i k} \in[1 / 2,1)$ which can be interpreted as a customer satisfaction level (Silva Filho and Ventura, 1999).

\subsection{The NFC Controller}

The NFC policy is computed as follows: At each period $\mathrm{k}$, the current level of inventory is observed by the Kalman filter estimator $\mathrm{x}_{\mathrm{k} \mid \mathrm{k}}^{\mathrm{i}}$. This estimation is than used as initial inventory $\left(\hat{x}_{k}=x_{k \mid k}^{i}\right)$ to compute the sequential open-loop policy $\left(\hat{\mathrm{u}}_{\mathrm{k}}^{*}, \hat{\mathrm{u}}_{\mathrm{k}+1}^{*}, \ldots, \hat{\mathrm{u}}_{\mathrm{T}}^{*}\right)$ that minimizes the modified MVP:

$$
\begin{aligned}
& \underset{\mathrm{u}_{\mathrm{ik}}}{\operatorname{Min}} \sum_{\mathrm{i}=1}^{\mathrm{N}}\left\{\sum_{\mathrm{k}=0}^{\mathrm{T}} \mathrm{F}\left(\hat{\mathrm{x}}_{\mathrm{ik}}\right)+\sum_{\mathrm{k}=0}^{\mathrm{T}-1} \mathrm{~g}\left(\hat{\mathrm{u}}_{\mathrm{ik}}\right)+\mathrm{K}_{\mathrm{i}}\right\}+\sum_{\mathrm{k}=0}^{\mathrm{T}-1}\left[\mathrm{r}\left(\mathrm{w}_{\mathrm{k}}\right)+\mathrm{p}\left(\mathrm{z}_{\mathrm{k}}\right)\right] \\
& \text { s.t. } \\
& \hat{\mathrm{x}}_{\mathrm{i}, \mathrm{k}+1}=\hat{\mathrm{x}}_{\mathrm{ik}}+\hat{\mathrm{u}}_{\mathrm{ik}}-\hat{\mathrm{d}}_{\mathrm{ik}} ; \quad \hat{\mathrm{x}}_{\mathrm{i} 0}=\mathrm{E}\left(\mathrm{x}_{\mathrm{i} 0} \mid \mathrm{I}_{\mathrm{k}}\right) \\
& \hat{\mathrm{x}}_{\mathrm{ik}} \geq \underline{\mathrm{x}}_{\mathrm{ik}}+\sigma_{\mathrm{d}_{\mathrm{i}}} \cdot \sqrt{\mathrm{k}} \cdot \Phi_{\varepsilon_{\mathrm{x}}}^{-1}\left(\alpha_{\mathrm{ik}}\right)=\underline{\mathrm{x}}_{\alpha}^{\mathrm{i}}(\mathrm{k}) \\
& \sum_{\mathrm{i}=1}^{\mathrm{N}} \eta_{\mathrm{i}} \cdot \hat{\mathrm{u}}_{\mathrm{ik}}-\mathrm{w}_{\mathrm{k}}-\mathrm{z}_{\mathrm{k}}=0 \\
& \sum_{\mathrm{i}=1}^{\mathrm{N}} \pi_{\mathrm{i}} \cdot \hat{\mathrm{u}}_{\mathrm{ik}} \leq \overline{\mathrm{U}} \\
& \hat{\mathrm{u}}_{\mathrm{ik}}, \mathrm{z}_{\mathrm{k}} \geq 0 \text { and } 0 \leq \mathrm{w}_{\mathrm{k}} \leq \overline{\mathrm{W}}_{\mathrm{k}}
\end{aligned}
$$

Only the first element of the sequence, i.e, $\hat{\mathrm{u}}_{\mathrm{k}}^{*}$ is used for managerial purpose, the remainder of elements in the production sequence - that is, $\left(\hat{\mathrm{u}}_{\mathrm{k}+1}^{*}, \ldots, \hat{\mathrm{u}}_{\mathrm{T}}^{*}\right)$ are completely ignored. The procedure is repeated whenever new observation is taken.

As a result, the modified MVP must be solved $\mathrm{T}$ times during the operation of the NFC. Note that such an operation can be seen as a particular type of rolling horizon where the planning horizon $\mathrm{T}$ is preserved fixed. In this case, the revised production level $\hat{\mathrm{u}}_{\mathrm{k}}^{*}$ is taken from the first element of the production sequence $\left(\hat{\mathrm{u}}_{\mathrm{k}}^{*}, \hat{\mathrm{u}}_{\mathrm{k}+1}^{*}, \ldots, \hat{\mathrm{u}}_{\mathrm{T}}^{*}\right)$ that is generated by solving the modified MVP for the following time scales $[\mathrm{k}, \mathrm{T}],[\mathrm{k}+1, \mathrm{~T}], \ldots,[\mathrm{T}-1, \mathrm{~T}]$; with $\mathrm{k}=0,1, \ldots, \mathrm{T}-1$.

\section{EXAMPLE}

A simple example of a hypothetical company that produces two different kinds of goods is considered now. Such products are strongly influenced by the fluctuation of demands, and the inventory level is not perfectly known due to factors as obsolescence, pilferage and other factors. The manager desires to obtain a plan that minimizes the total production cost, and at the same time, to be able to reduce the risk of stockout. The main firm's data are listed in table 1 . The planning horizon is one year with monthly discrete time (i.e., $\mathrm{T}=12$ months). The upper bound work force $\overline{\mathrm{W}}_{\mathrm{k}}$ is assumed constant for each period $\mathrm{k}$ (i.e., = 200 man-hour) In this example, the inventory, production, regular and overtime man-hour workforce costs are assumed quadratic functions; the deterministic mathematical expression of these costs is described by the criterion $\mathrm{J}($.) , defined as follows:

$$
\mathrm{J}_{u}=\sum_{\mathrm{k}=1}^{\mathrm{T}}\left\{\mathrm{h}_{\mathrm{ik}} \cdot \hat{\mathrm{x}}_{\mathrm{ik}}^{2}+\mathrm{c}_{\mathrm{ik}} \cdot \hat{\mathrm{u}}_{\mathrm{ik}}^{2}+\mathrm{r} \cdot \omega_{\mathrm{k}}^{2}+\mathrm{p} \cdot \mathrm{z}_{\mathrm{k}}^{2}\right\}+\mathrm{K}_{\mathrm{i}}
$$

where $\mathrm{K}_{\mathrm{i}}=\sigma_{\mathrm{d}_{\mathrm{i}}}^{2} \sum_{\mathrm{k}=0}^{\mathrm{T}} \mathrm{k} \cdot \mathrm{h}_{\mathrm{ik}}$ denotes the integration constant. 
From the above information, and using the notation given in (6)-(7), the statistics (mean and variance) related with the quantity ordered for each product, are given as follows:

(i) product 1: $\sigma_{\mathrm{d} 1}=40$ and the monthly mean $\mu_{\mathrm{d} 1}$

\begin{tabular}{|l|l|l|l|l|l|}
\hline Jan & Feb & Mar & Apr & May & Jun \\
\hline 134 & 168 & 152 & 146 & 170 & 174 \\
\hline \hline Jul & Ago & Sep & Oct & Nov & Dec \\
\hline 208 & 180 & 160 & 170 & 188 & 208 \\
\hline
\end{tabular}

(ii) product 2: $\sigma_{\mathrm{d} 2}=20$ and the monthly mean $\mu_{\mathrm{d} 2}$

\begin{tabular}{|l|l|l|l|l|l|}
\hline Jan & Feb & Mar & Apr & May & Jun \\
\hline 200 & 250 & 150 & 120 & 200 & 250 \\
\hline \hline Jul & Ago & Sep & Oct & Nov & Dec \\
\hline 188 & 200 & 170 & 170 & 160 & 180 \\
\hline
\end{tabular}

The customer service level is considered the same for the two products (i.e., $\alpha_{1 \mathrm{k}}=\alpha_{2 \mathrm{k}}, \forall \mathrm{k}$ ). In this case, the value of $\alpha$ is set equal to 0.75 . The objective is to analyze the behavior of the production process when the goal fixed by the manager is to satisfy demand at least $75 \%$ of time.

Table 1 Firm's data

\begin{tabular}{|c|c|c|}
\hline Data (per unity) & Prod. 1 & Prod. 2 \\
\hline \hline Production costs $\left(\mathrm{c}_{\mathrm{i}}\right)$ & $\$ 0,50$ & $\$ 0,60$ \\
\hline Inventory costs $\left(\mathrm{h}_{\mathrm{i}}\right)$ & $\$ 2,00$ & $\$ 3,00$ \\
\hline Initial Inventory $\left(\mathrm{x}_{\mathrm{i} 0}\right)$ & 200 & 200 \\
\hline Productivity rate $\left(\pi_{\mathrm{i}}\right)$ & $0.8 /$ unid. & 0.2 /unid. \\
\hline Man hour factors $\left(\eta_{\mathrm{i}}\right)$ & 0.5 & 0.5 \\
\hline \hline \multicolumn{3}{|c|}{$\sigma_{\mathrm{v}_{1}}=\sigma_{\mathrm{v}_{2}}=30($ error standard deviation) } \\
$\mathrm{r}_{\mathrm{k}}=\$ 5,00$ (regular cost); $\mathrm{p}_{\mathrm{k}}=\$ 50,00$ (overtime) \\
$\underline{\mathrm{x}}_{1 \mathrm{k}}=80 \quad$ and $\underline{\mathrm{x}}_{2 \mathrm{k}}=40$ \\
\hline \multicolumn{3}{|c}{} \\
\hline
\end{tabular}

Analysis of the results: The idea is to simulate the inventory process using the NFC procedure. The total production cost obtained with the problem under imperfect information and with the system being operated by a NFC policy is compared to the same problem but under perfect information with the system now being operated by NFC and open-loop policies. Note that, in open-loop operation, the unique information about the inventory levels used to solve the problem (15)-(20), is the initial level of inventory measured at instant $\mathrm{k}=0$. As a result, to obtain the open-loop sequence, the modified MVP is solved once at time over the planning horizon $[0, \mathrm{~T}]$. This open-loop characteristic contrasts with operation of NFC procedure whose policy is provided by solving problem (15)-(20) in a total of $\mathrm{T}$ times over the planning horizon.

The simulation structure of the system, operating under imperfect information of state (inventory level), is shown in figure 1. For comparing different policies, it is assumed the system operates under perfect information (i.e., $\mathrm{y}_{\mathrm{ik}}=\mathrm{x}_{\mathrm{ik}}$ ). In that case, an open-loop policy can be applied to the system by putting the switch "off" for all period $k>0$. On the other hand, a sub-optimal NFC policy can be applied to the system by putting the switch "on" for all $\mathrm{k}$.

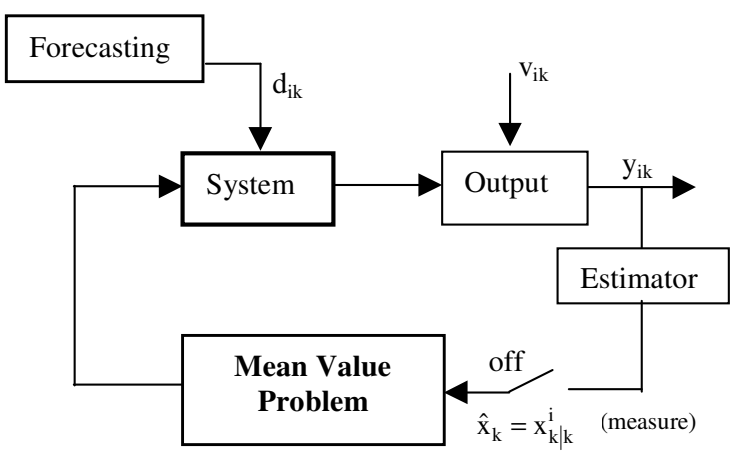

Fig.1. NFC and open-loop Simulation Schemes

Considering the three situation mentioned above, the figures 2,3 and 4 illustrates the behavior of the inventory, production, and regular and overtime manhour levels required to meet the demand for the two products. Note that for the product 1 , the inventory and production trajectories are represented by solid lines and, for product 2, they are represented by dotted lines.

Some conclusions obtained from comparing the three figures were: (a) the production levels remain relatively stable over the periods. It is a smoothing production policy; (b) the inventory levels related to the open loop solution (figure 4) increase over the periods, the reason of this, is that the unique information available about the inventory is given by initial inventory $\mathrm{x}_{\mathrm{i} 0}$, any other measured is completely ignored. On the other hand, the inventory trajectories related to NFC policies (see figure 3 and 4) decreases, in a fluctuating pattern, over the time. Such behavior is due to the fact that NFC takes into account measures about the inventory level in each period $\mathrm{k}$ of the system operation; (c) the work force level increases over the periods. The maximum level of regular man-hour $\left(\overline{\mathrm{W}}_{\mathrm{k}}=200\right)$ is reached between period 4 and 7 . Note that in these periods also occurs a pick of overtime consume. In general, the trajectories of regular and overtime workforce (in man-hours) is very similar in the three cases analyzed. This characteristic result of the smooth behavior of production policies; and (d) comparing the cost of applying NFC to the system under perfect information ( $\mathrm{J}_{\mathrm{NFC}}^{\text {imperf }}$ ) with the cost of applying NFC $\left(J_{N F C}^{\text {perf }}\right.$ ) and open-loop ( $J_{\mathrm{OL}}^{\text {perf }}$ ) to the system under perfect information, results that $\mathrm{J}_{\mathrm{NFC}}^{\text {perf }}<\mathrm{J}_{\mathrm{NFC}}^{\text {imperf }}<\mathrm{J}_{\mathrm{OL}}^{\text {perf }}$. The legends of figures $2-4$ have the respective value of costs. Analyzed them, it is possible to conclude that the NFC is quasi-adaptive approach, see Bertesekas (1995) for details about the notion of adaptivity. 


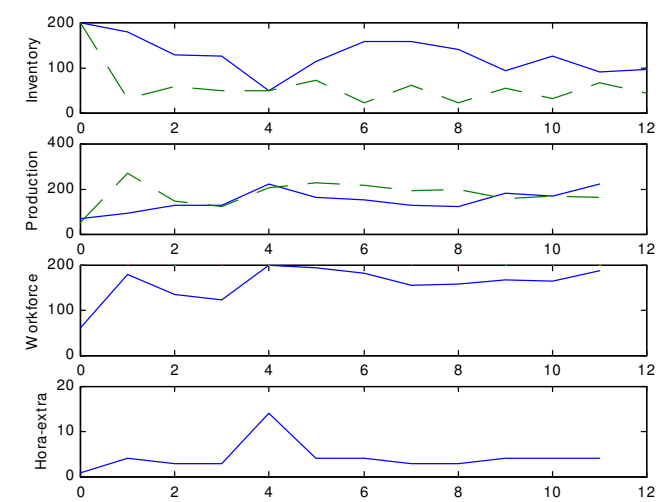

Fig. 2. Trajectories of NFC approach (imperfect information). $\mathrm{J}_{\mathrm{NFC}}^{\text {imperf }}=1.230 .791,00$

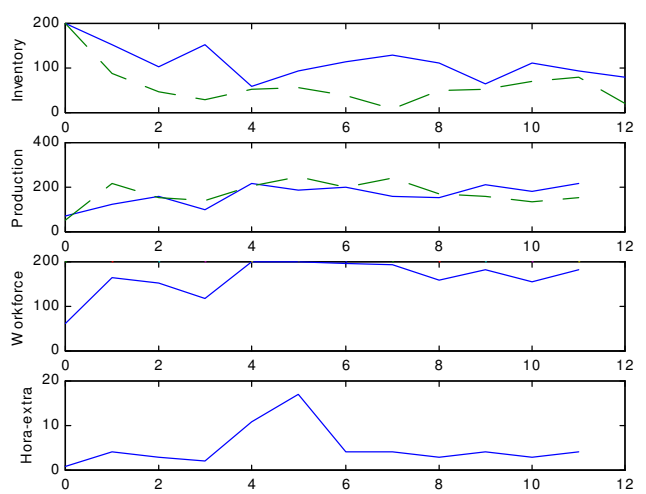

Fig. 3. Trajectories of NFC procedure (perfect information). $J_{\mathrm{NFC}}^{\text {perf }}=1.166 .357,00$.

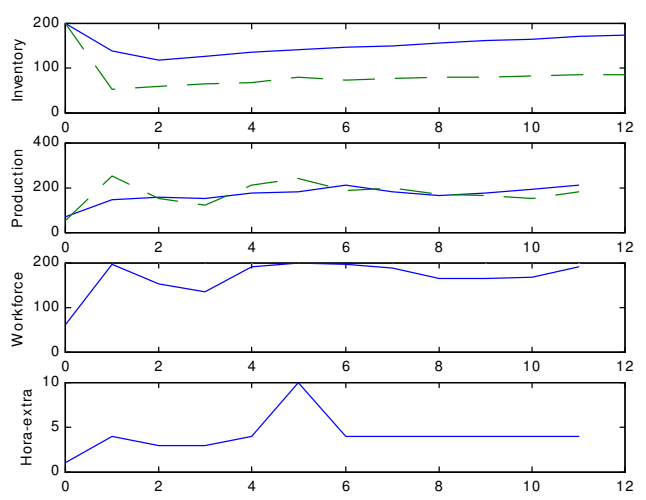

Fig. 4. Open-loop trajectories. $\mathrm{J}_{\mathrm{OL}}^{\text {perf }}=1.629 .036,00$

\section{CONCLUSION}

A multi-period multi-product stochastic production planning problem with constraints on main decision variables and system operating under imperfect information of state was investigated. Since finding true optimal solution to this problem is a hard task, a sub-optimal approach named as NFC was considered. The selection of this approach can be explained by its easy numerical implementation, and also because it does not require large storage capacity of the digital computer. The conventional mean value problem
(MVP) was reformulated to include more information about the statistic moments of the stochastic problem. This aspect improves the solution provided by the NFC approach. This procedure was simulated and compared with open-loop and NFC approaches applied to a system operating under perfect information. From the results, it was possible to shown that even the system operating under imperfect information, the NFC approach give best solution than the one give by open-loop solution. The feedback mechanism associated with the procedure helps to obtain a revised production plan. Note that, since the production process is a dynamic system, a constant revision of the plan is a very important task used in the management process.

Acknowledgement: The work is supported by $\mathrm{CNPq}$ under grant No. 305081/20020

\section{REFERENCES}

Astron, K. J. (1970). Introduction to Stochastic Control Theory, Academic Press, New York.

Bertesekas, D. P. (1995): Dynamic Programming and Optimal Control Vol. 1., Athena Scientific, Belmont, USA.

Chou, Y. (1972): Probability and Statistics for Decision Making, Holt, Rinehart, Winston, NY.

Hax, A. C. and Candea, D. (1984). Production and Inventory Management. Prentice Hall, Englewood Cliffs, New York.

Kleindorfer, P. R. (1978) Stochastic Control Models in Management Science: Theory and Computation, TIMS - Studies in the Management Science (Ed. Bensoussan, Crouhy and. Proth), V. 9, North Holland.

Minoux, M. (1983) Programmation Mathematique: Theory et Algorithmes, Dunod, Paris.

Neck, R. (1984): Stochastic Control Theory and Operational Research, European Journal of Operational Research, 17, pages.: 283-301.

Papoulis, A. (1991) Probability, Random Variables, and Stochastic Processes, McGraw-Hill.

Silva Filho, O. S. and Cezarino W. (2002). Comparison among Sequential Sub-optimal Approaches with Focus on Stochastic Production Planning, 15 IFAC World Congress, Vol. 1, Barcelona, Spain.

.Silva Filho, O. S. (2001). Linear Quadratic Gaussian Problem with Constraints Applied to Aggregated Production Planning, Proceeding of the American Control Conference, Arlington.

Silva Filho, O. S. and Ventura S. D. (1999). Optimal Feedback Control Scheme Helping Manager to Adjust Aggregate Industrial Resources, Control Engineering Practice, Volume 7, pages 555-563.

Tsubone, H.; H. Matsuura; \& T. Tsutsu (1991)'Hierarchical Production Planning System for a Two-Stage Process", Intern. Journal Prod. Research, Vol. 29, No. 4, pp. 769-785. 